\title{
Higher Education in Saudi Arabia: Challenges to Achieving World-Class Recognition
}

\author{
Eman Abdulrahman Radi Alharbi
}

\begin{abstract}
Nowadays, the Kingdom of Saudi Arabia's crown prince Mohammed bin Salman has adopted a new vision and strategies for the development of Saudi Arabia to become one of the most advanced countries in the world in economics and education by 2030. Higher education heads the list of the strategies to join the world classes and be internationalized. The purpose of this paper is to discuss dispute the challenges that face higher education in Saudi Arabia. The major challenges facing Saudi universities are research productivity, accreditation, and improving quality. Therefore, the paper will scrutinize some fundamental changes needed in the development process. Further, the definition of World-Classes and with the importance of it will describe in the paper. The paper will show the influence of economic statues in higher education in Saudi Arabia. Furthermore, a dissection of conceptual bases will also be touched on in the paper.
\end{abstract}

Index Terms-World-classes, higher education, and development.

\section{INTRODUCTION}

The Kingdom of Saudi Arabia is the largest country on the Arabian Gulf. Most higher education universities in the kingdom depend on the national resources that come from the oil explosion. According to Amani Hamdan (2013), "Economic development is another trend that is affecting Saudi's education" (p. \#). Additional researcher have confirmed that even though the Kingdom of Saudi Arabia has a heavy reliance on oil revenue, the kingdom has the same issue as China in that it is moving toward a diverse economy that places priority on high quality of skills and knowledge (Zha, 2011).

However, the economy has changed recently in the kingdom, and the government has established a new strategy to increase the productivity of the economy (Alamri, 2011; Hamdan, 2013; Hilal, 2013). As a consequence of the new

Vision for the kingdom, it has become more challenging to meet the country's higher education expectations. Since the beginning of the year 2016, the Kingdom of Saudi Arabia's crown prince Mohammed bin Salman has adopted a new vision and strategies for the development of Saudi Arabia to become one of the most advanced countries in the world in terms of the economy and education in 2030. Therefore, university leaders in the kingdom have responded to the development by becoming with world-class universities and internationalizing higher education. For the most part, the

Manuscript received September 1, 2016; revised November 12, 2016.

Eman A. Alharbi is with the Tennessee State University, USA (e-mail: Emey_a407@yahoo.com). major challenges facing Saudi universities are research productivity, accreditation, and improving quality.

\section{BACKGROUND OF HIGHER EDUCATION IN THE KINGDOM OF SAUDI ARABIA}

The Kingdom of Saudi Arabia is over 2 million square kilometers in area, comprising 13 administrative provinces (Hilal, 2013). The total population as of 2016 is more than $32,430,000$, made up of $44.8 \%$ women and $55.2 \%$ men. The largest percentage of the population's age is from 15 to 64 years old. The Kingdom of Saudi Arabia is the only country in the world that has a gender segregation policy in the entire public sector, especially universities, except for the medical sector and King Abdullah University of Science and Technology (Hilal, 2013). The kingdom has twenty-five public universities and eight private universities located in different geographic regions in the kingdom (Hamdan, 2013). The Ministry of Education governs all the universities in the kingdom. Additionally, student enrollment has increased due to the increased population, but more than 60,000 students are unable to study in the universities in the kingdom. Because of the increased population and the growing demand of the economy, the King Abdullah Scholarship Program was established in 2005 (Alamri, 2011; Hamdan, 2013; Hilal, 2013). The program aims to send students to study overseas in order to fulfill the job market need and meet the growing demand (Alamri, 2011; Hamdan, 2013; Hilal, 2013).

\section{WORLD - CLASS UNIVERSITIES}

Why is being labeled a world-class university very important to being competitive for universities across the world? A world - Class university is a concept or honorific that symbolizes the university's research productivity and the quality of learning. Levin, Henry $M$ \& Jeong, Dong\& Dongshu, Ou (2006) have described a significant feature of the world-class university:

In general, there is wide agreement that great universities have three major roles: (1) excellence in educating their students; (2) research, development, and dissemination of knowledge; and (3) activities contributing to the cultural, scientific, and civic life of society. Excellence in education means the resources and organization of undergraduate, graduate, and professional instruction and educational opportunities for students. Clearly, this goal requires outstanding faculty, high quality teaching and other instructional activities, and availability of good libraries, 
laboratories, and other pertinent facilities as well as highly prepared and motivated students who serve to educate through their peer influence. Research, development, and dissemination of knowledge refer to the embryonic identification, growth, and extension of concepts and ideas as well as their transformation into applications, goods, and services that enhance understanding and welfare. Activities contributing to the cultural, scientific, and civic life of society are many and varied, but include conferences, publications, artistic events and forums as well as provision of services (e.g. medical clinics and hospitals or museums) that engage and contribute to the larger community including the regional, national, and international communities. (p. 2\&3)

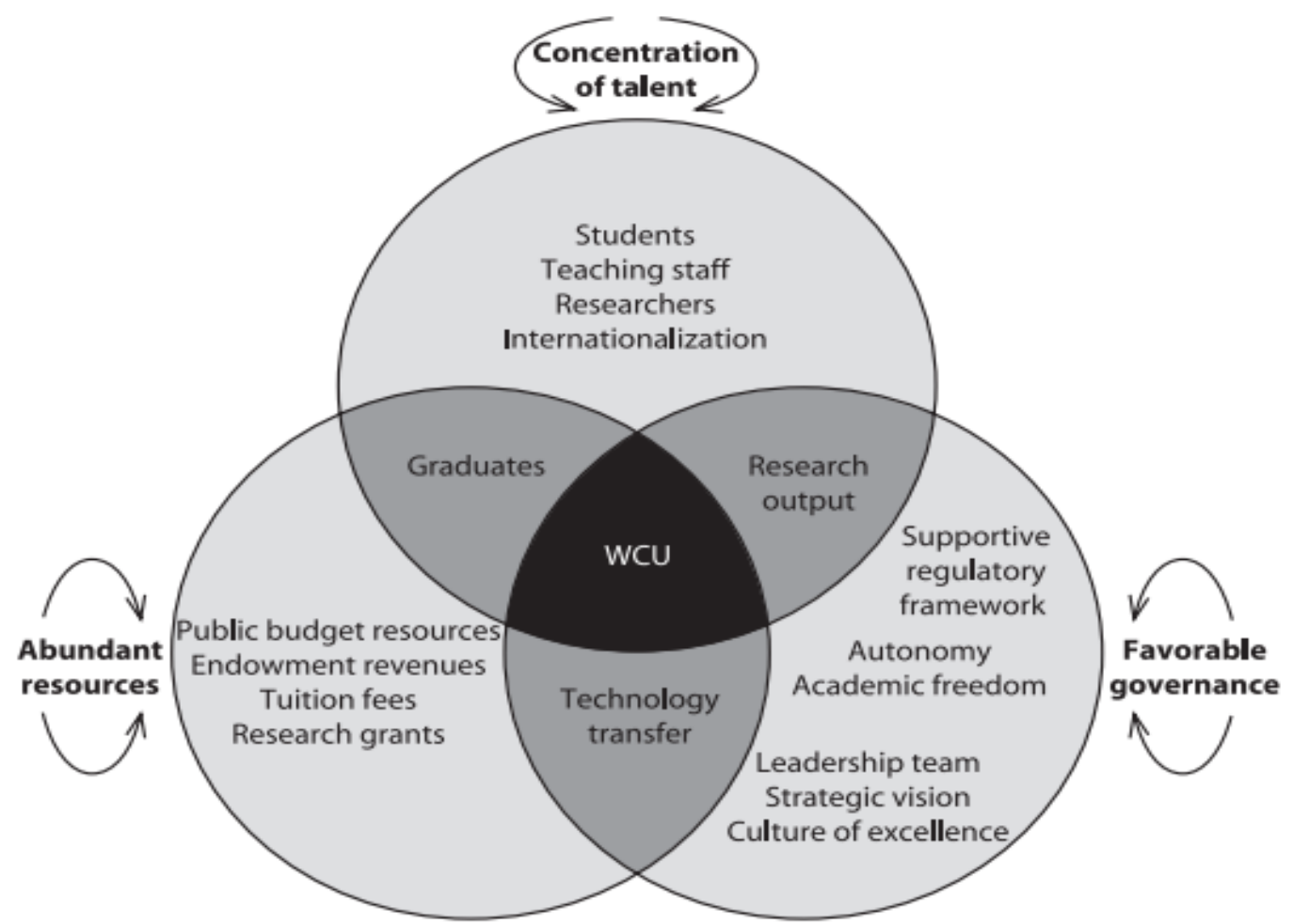

Fig. 1. The characteristics of a world-class university and alignment of key factors.

Source: Salmi p.8 (2009).

The establishment of a world-class university is competitive over a decade. Hanaa Ouda and Khadri Ahmed (2015) confirmed this via a conceptual view presented in their study titled "Strategic Approach for Developing World-Class Universities in Egypt." They expressed the benefit of universities in developed countries becoming world-class universities. They showed the vital role of being a world-class university, as it helps to develop the capacity to compete in the global higher education marketplace through the acquisition and creation of advanced knowledge. Justin Lin (2009), noted the importance and benefit of universities becoming World-Class Universities, since the status enhances a university's worldly reputation and allows the university to play a role in the global marketplace. Specifically, Lin stated, "No longer are countries comfortable with developing their higher education systems to serve their local or national communities. Instead, global comparison indicators have gained significance in local development of universities" (p. $\mathrm{X}$ as cited by Salmi, 2009).

The majority of world-class universities are from Western countries, specifically, the United States and the United Kingdom.

Furthermore, there are notable characteristics of world-class universities, as recognized by Salmi (2009), which are the following:

- Concentration of talent

- Abundant resources

- Favorable governance

All the previous characteristics relate to each other and are combined in three major areas, which are graduates, research output, and technology transfer. a) Concentration of talent is related to the first component that characterizes World-Class Universities. The high-quality and top students and faculty always selected by world- class universities and Ivy League universities in the United States or Oxford and Cambridge in the United Kingdom. b) Abundant resources are the second component that characterizes World-Class Universities. According to Salmi (2009),

"In response to the huge costs involved in running a complex research-intensive university. These universities have four main sources of financing: government budget funding for operational expenditures and research, contract research from public organizations and private firms, the financial returns generated by endowments and gifts, and tuition fees." (p. 23)

c) Favorable governance is the third component that characterizes world-class universities because these universities, such as Harvard and Oxford, have regulated 
effectively in autonomy and a shared governance framework that enjoy academics, leaders, faculty, and students. According to Salmi (2009),

"Other crucial governance features are needed such as inspiring and persistent leaders, a strong strategic vision of where the institution is going, a philosophy of success and excellence, and a culture of constant reflection, organizational learning and change." (p. 46).

\section{Challenges Facing SAUdi Higher Education UNIVERSITIES}

Saudi's higher education institutions have been trying to win the race and to be considered world-class universities. However, the universities' education systems have faced major challenges in becoming World-Class Universities. The challenges are research productivity, accreditation, and improving quality. These challenges have been argued by several authors in each chapter in Larry Smith and Abdulrahman Abouammoh's (2013) book Higher Education in Saudi Arabia: Achievement, Challenge, and Opportunity.

According to Mazi and Altbach (2013),

"Research is the only aspect of a university's work that can be easily measured cross-nationally. Counting numbers of articles published and to some extent measuring their impact is an accepted part of bibliometrics and is done by companies such as Thomson Reuters. Other metrics used by the rankers include research funds obtained by universities, qualifications of the faculty, and student selectivity." (p. 13)

Therefore, one of the most important aspects and key points of world-class universities is research. Numerous educational researchers have confirmed that the research productivity of a university contributed to improving the university's ranking. Furthermore, Smith and Abouammoh (2013) presented a contrasting argument regarding the challenges facing Saudi universities of producing research and becoming world-class universities; they stated that "if the Saudi higher education system is to achieve its stated goal of having its leading universities recognized internationally as 'world-class,' then it must give urgent priority to its research effort, because global university ranking systems are heavily based on the quality and quantity of an institution's research activity and outcomes." On the other hand, the fact making research productivity a challenge to Saudi universities is that there is a low number of articles published and research performed by administrators, academics, and students. The low rate of publication is due to several reasons, including lack of knowledge, lack of awareness, and English proficiency.

Numerous studies have confirmed that higher education institutions are seeking academic quality become to more globalized and for the benchmark accountability to produce successful outcomes (Al-Musallam, 2009; Hazelkorn, 2007; Alt, H., 2002; Koz'min’sk, 2002; Mazi \& Altbach, 2013). Therefore, the standards of a university must be reviewed and its quality maintained by a truly quality independent governance body in order to achieve international and global economic growth (Al-Musallam, 2009).

Consequently, Saudi universities need to understand that international accreditation of institutions is extremely important in order to be recognized internationally and globally via the quality assurance level of the universities. Therefore, accreditation and quality are other challenges facing the Saudi university education system in attempting to become a World-Class Universities. Due to the internationalization accreditation position, international accreditation has become an urgent necessity in order to promote global education in Saudi Arabian universities (Hamdan, 2013). The dream is to be internationally recognized, but unfortunately, the reality is that many Saudi universities lack quality institutions, standards, effectiveness, and efficiency, which has caused their lack of international recognition (ranked) and prevented them from becoming world-class universities. However, some programs have received international accreditation, such as some diploma education programs that have been accredited by the British Quality Foundation (Hazelkorn, 2011). If one of the Saudi universities receives international institution accreditation, then the university will have a change in its performance, reputation, and quality improvement, becoming a world-class university in the Arabian Gulf region.

\section{CONCLUSION}

The higher education system in Saudi Arabia needs to adopt a benchmark strategy for resolving the challenges that face the universities in order to meet the growing demand of the economy and fulfill the vision of the prince Muhammed bin Salmman for the kingdom. Leaders in the universities must face these challenges with vigor to improve the universities performance, reputation, and quality outcomes in the coming five years.

\section{REFERENCES}

[1] H. Alt, "Benchmarking in the globalized world and its impact on South African higher education," South African Journal of Higher Education, vol. 16 , no. $1,2002$.

[2] A. Majed, "Higher education in Saudi Arabia," Journal of Higher Education Theory and Practice, vol. 11, no. 4, 2011.

[3] A. Al-Musallam, "Higher education accreditation and Quality Assurance in the Kingdom of Saudi Arabia," presented at the First National Conference for Quality in Higher Education, Riyadh, Saudi Arabia, 2009.

[4] A. Hamdan, "An exploration into" private" higher education in Saudi Arabia: Improving quality and accessibility? The ACPET Journal for Private Higher Education, vol. 2, no. 2, 2013.

[5] H. Ahmed and K. Ouda, "Strategic approach for developing world-class Universities in Egypt," Journal of Education and Practice, vol. 6, no. 5, pp. 125-145, 2015.

[6] E. Hazelkorn, Rankings and the Reshaping of Higher Education: The Battle for World-Class Excellence, Basingstoke: Palgrave, 2011.

[7] K. T. Hilal, "Between the fears and hopes for a different future for the nation-states: Scholarship programs in Saudi Arabia and united Arab emirates from a public policy standpoint," IJHE International Journal of Higher Education, vol. 2, no. 2, 2013.

[8] A. Koz'min'ski, 'Ranking and league tables of higher education institutions," Higher Education in Europe, vol. 27, no. 4, pp. 365-371, 2002.

[9] M. L. Henry, J. Dong, and D. S. Ou, "What is world class University?" in Proc. the 2006 Conference of the Comparative and International Education Society, Honolulu, Hawaii, 2006. 
[10] M. Abdulhalem and P. G. Altbach, "Dreams and realities: The world-class idea and Saudi Arabian higher education," Higher Education in Saudi Arabia Achievements, Challenges and Opportunities, Springer Netherlands, pp. 1571-0378, 2013.

[11] J. Salmi, "The challenge of establishing world-class universities," 2009.

[12] S. Larry and A. Abouammoh, "Higher education in Saudi Arabia: Achievements, challenges and opportunities," vol. 1, no. 40, Springer Netherlands, pp.1571-037, 2013.

Eman A. Alharbi was born in 1987. She is with doctor of education in administration and supervision in higher education at the Tennessee State University; Nashville, TN until 2017. She received her master of educationin administration and supervision in higher education at the Middle Tennessee State University; Murfreesboro, TN in 2013. She received her bachelor degree of education at the Islamic studies Umm Alqura university, Makah, Saudi Arabia in 2009.
She had experienced on a professional teaching at Tennessee State University in 2015 and she worked as administrative assistance at Um Alqura charity association, and worked as a teacher at 14th elementary school at Saudi Arabia in 2008. She had presented in September 20-22,2015 on the Third 21st Century Academic Forum Conference at Harvard, and in February, 2014 on 20 The annual on Adult Learner at Middle Tennessee State University. Eman A. Alharbi published two papers. One is titled "Raising Public School Funds in Saudi Arabia by Applying Strategies Used in the United States of America" published by Third 21 st CAF Conference at Harvard, in Boston, USA. September 2015. Second is titled "Adult Characteristic Learning" published by Review of Higher Education and Self-Learning. Jun 2016.

Eman Abdulrahman Alharbi has award Scholarship from Government of Saudi Arabia, 2010 